Letter to the editor

\title{
Monitoring Reasons for Encounter via an Electronic Patient Record System: the Case of a Rural Practice Initiative
}

\section{Spyridon Klinis ${ }^{1}$, Adelais Markaki ${ }^{\circledR}{ }^{\varpi}$, Dimitrios Kounalakis ${ }^{3}$, Emmanouil K. Symvoulakis ${ }^{4}$}

1. Primary Health Care Unit of Alonakia, Siatista, Greece

2. Department of Social Medicine, Faculty of Medicine, University of Crete, Greece

3. Private Family Practice Unit in Heraklion, Crete, Greece

4. Private Family Practice Unit in Heraklion, Crete, Greece

Corresponding author: Adelais Markaki, APRN-BC,PhD, Dept. of Social Medicine, Faculty of Medicine, Univ. of Crete, P.O. Box 2208, Heraklion, Crete, 71003. E-mail: adamarkaki@med.uoc.gr Tel. 0030-2810-394619

(C) Ivyspring International Publisher. This is an open-access article distributed under the terms of the Creative Commons License (http://creativecommons.org/ licenses/by-nc-nd/3.0/). Reproduction is permitted for personal, noncommercial use, provided that the article is in whole, unmodified, and properly cited.

Received: 2012.08.07; Accepted: 2012.09.17; Published: 2012.10.06

\begin{abstract}
The objective of this brief communication was to tabulate common reasons for encounter in a Greek rural general practice, as result of a recently adopted electronic patient record (EPR) application. Twenty encounter reasons accounted for 3,797 visits (6l\% of all patient encounters), whereas 565 other reasons accounted for the remaining 2,429 visits (39\%). Number one reason for encounter was health maintenance or disease prevention seeking services, including screening examinations for malignancies, immunization and provision of medical opinion reports. Hypertension, lipid disorder and ischemic heart disease without angina were among the most common reasons for seeking care. A strengths/weaknesses/opportunities/threats (SWOT) analysis on the key role of an EPR system in collecting data from rural and remote primary health care settings is also presented.
\end{abstract}

Key words: patient encounter, rural practice, general practice, electronic patient record, Greece

Information technology (IT) is increasingly seen as an important venue for improving quality of health care and patient safety [1-3]. An essential component of IT is the electronic patient record (EPR), defined as a systematic collection of electronic health information about individual patients or populations [4]. It can be shared across free-standing health care units as well as integrated delivery networks and may include a range of data, such as medical history, medication and allergies, laboratory test results, radiology images, vital signs, and billing information. In comparison to conventional paper-based records, EPR systems may decrease medical errors [2] and allow general practitioners to pursue more effective interventions during their daily routines [1]. Furthermore, EPR data can be tabulated for surveillance of communicable diseases or community risk factors, statistical report- ing of quality improvement efforts and strategic planning of resource allocation. The use of EPR for the management of clinical information and classification of the reasons for seeking primary health care (PHC) is becoming imperative, particularly for countries with limited resources, facing severe austerity measures, such as Greece [5].

Although several studies have been carried out in Europe with a focus on healthcare utilization, PHC utilization should always be examined in the light of conceptual models to capture this complex, multidimensional concept [6-10]. According to Andersen's behavioral model, people may be predisposed to using health services but also need some means of obtaining them [11]. Thus, the rural/urban nature of the community in which a patient lives can be viewed as one of the enabling factors. An application of the be- 
havioral model in a study of PHC utilization in Gaza Strip, Palestine, showed that frequent use was associated with older age, marital status, poor living conditions, unemployment, higher income, poorly rated health status and current smoking habits [12].

The aim of this letter is to tabulate common reasons for encounter in a Greek rural general practice, as result of a recently adopted EPR application. It is further intended to demonstrate via a SWOT analysis the key role of an EPR system in collecting, analyzing and evaluating clinical data from rural and remote PHC settings.

Systematic use of EPR in Greece is not yet available despite some sporadic efforts. A previously developed EPR, within the context of a PhD thesis at the University of Crete [13], was installed in the Alonakia PHC setting as an individual unit initiative, a rural area in Northern Greece. Data were collected between June 2008 and January 2011. Dataset entry included reasons for encounter, medical interventions, lab test results and vital signs. Direct coding was performed by the GP using the International Classification of Diseases in Primary Care (ICPC-2) [14] as well as the International Classification of Diseases (ICD-10) classification [15].

$$
\text { A SWOT (Strengths/Weaknesses/ }
$$

Opportunities/Threats) analysis outlining expected benefits and risks from the implementation of an EPR system in regards to reasons for patient encounter is presented in Figure 1.

\section{Strengths}

- Real-time, point-of-care data entry

- Standardized classification of reasons for patient encounter (ie. ICD-10 or ICPC-2)

- Effortless, remote management of clinical information

- Improved efficiency (i.e. avoidance of diagnostic test duplication)

- Monitoring of morbidity local traits

\section{Weaknesses}

- Installment \& maintenance cost (cost savings for large integrated institutions, not small rural practices)

- Reduced productivity during initial implementation phase (exacerbated by limited workforce in rural PHC units)

- Conflicting evidence in literature in regards to improving quality of rural care

- Synchronization of records (may be difficult to update records in a coordinated fashion at two locations where care is provided simultaneously)

\section{Opportunities}

- Data banking (preservation \& storage)

- Data synthesis (i.e. creating epidemiologic profiles of catchment area residents)

- Ability to synch up with mobile devices, allowing access to patient records from remote locations

- Adjustment to regulatory compliance (i.e. NHS or Insurance carrier new mandates)

- Networking (ie. Practice based research network in primary care with access to EPR system)

\section{Threats}

- Adverse events may occur as a result of shortcomings of EPR system users, equipment or organizational/system capacity

$>$ Human threats (i.e. careless employees or hackers)

$>$ Natural and environmental threats (i.e. flood, fire)

$>$ Technology failures (i.e. system crashing)

- Privacy and confidentiality concerns (i.e. unauthorized transmittal of patient record information)

- Health professional liability concerns (i.e. malpractice risk)

Figure I: SWOT Analysis of the role of an EPR system* in collecting, analyzing and evaluating "reason for encounter" data within a rural primary care setting. (*Information from Reference \#4). 
A total of 1,084 patients were registered in the EMR system accounting for 6,226 encounters over the study period. Male to female ratio was $0.7: 1$. The median age for men was 59.0 years (range 2-102 years) and for women 62.3 years (range 0.9-97 years) respectively. The most common reasons for encounter are shown in Table 1. Twenty encounter reasons accounted for 3,797 visits (61\% of all patient encounters), whereas 565 other reasons accounted for the remaining 2,429 visits (39\%). The number one reason for encounter was health maintenance or prevention seeking services, including screening examinations for malignancies and need for immunization. Hypertension, lipid disorder, ischemic heart disease without angina, type 2 diabetes mellitus and osteoporosis were listed as the top five reasons for encounter among all chronic disorders. The most frequent symptoms, classified as reasons for encounter, were abdominal pain, vertigo/dizziness and cough.

The emerging utilization pattern and morbidity profile of the rural population in our study shares quite a few similarities with the outcomes reported from other rural and urban general practice settings [16-19]. Despite the differences in methodology followed in previous studies, women accounted for the majority of visits in both rural and urban settings, with hypertension being the most frequent reason for encounter. The unexpectedly high demand for health promotion and/or disease preventive services from our rural patients was comparable, to some extent, to that reported by Mariolis et al [19], in their comparison study of urban vs. rural PHC settings.
In terms of the most frequently occurring symptoms, acute upper respiratory infection was in accordance with the finding from the urban setting [17], whereas vertigo was a common finding for both the urban study [17] and another rural study from Southeastern Greece [18]. A significant increase in outpatient clinic visits due to symptoms of vertigo and tinnitus has also been found in a recent urban study, lending support to similar observations from different sources of data [20].

EPR system use can provide a first glimpse concerning the health profile and the needs of a rural population, highlighting similarities and differences between rural versus urban PHC service seekers. Adoption of the same EPR system and methodology by neighboring PHC facilities may help threefold: a) individual health professionals could focus on the most common everyday encounter problems, enhancing their clinical performance, b) health teams could improve their planning, implementation and evaluation efforts in regards to community outreach and health promotion initiatives, and c) regional health authorities could develop a projection model, predicting future utilization patterns for PHC services, while taking measures to reduce unnecessary demand and to expand the clinical capacity of primary care providers.

Supporting individual unit efforts, while disseminating the knowledge and experience gained by inquiring primary care providers, could prove to be a priceless alternative to professional inertia in a country struggling with overgrowing PHC demands and drastically shrinking resources.

Table I: Distribution of cases by reason for rural general practice encounter.

\begin{tabular}{llll}
\hline Reason for encounter & ICPC-2 & Cases (n) & Percentage (\%)* \\
\hline Health maintenance/ prevention** & A98 & 1191 & 19.1 \\
Hypertension uncomplicated & K86 & 380 & 6.1 \\
Lipid disorder & T93 & 376 & 6.0 \\
Abdominal pain epigastric & D02 & 239 & 3.8 \\
Ischemic heart disease without angina & K76 & 224 & 3.6 \\
Osteoporosis & L95 & 158 & 2.5 \\
Diabetes non-insulin dependent & T90 & 154 & 2.5 \\
Upper respiratory infection acute & R74 & 115 & 1.8 \\
Vertigo / Dizziness & N17 & 114 & 1.8 \\
Oesophagus disease & D84 & 104 & 1.7 \\
Cough & R05 & 88 & 1.4 \\
Back syndrom without radiating pain & L84 & 85 & 1.4 \\
Depressive disorder & P76 & 82 & 1.3 \\
Acute bronchitis/bronchiolitis & R78 & 78 & 1.3 \\
Anxiety disorder/anxiety state & P74 & 75 & 1.2 \\
Osteoarthrosis of knee & L90 & 70 & 66 \\
Benign prostatic hypertrophy & Y85 & 1.1 \\
\hline
\end{tabular}




\begin{tabular}{llll}
\hline Constipation & D12 & 65 & 1.0 \\
Chronic obstructive pulmonary disease & R95 & 62 & 1.0 \\
Other & & 2429 & 39.0 \\
No disease*** & A97 & 71 & 1.1 \\
Total & & 6226 & 100 \\
\hline
\end{tabular}

*Rounded decimals

**Including ICD-10 codes for neoplasm screening examinations and immunizations.

***Including ICD-10 codes for general medical examination and issue of medical opinion report.

\section{Acknowledgements}

We are grateful to the academic staff of the Department of Social Medicine, University of Crete, for their eagerness to motivate research initiatives within family and social medicine.

\section{Authors' Contribution}

All authors contributed equally for this letter.

\section{Conflict of Interest}

We declare no conflict of interest.

\section{References}

1. Miller RH, Sim I. Physicians' use of electronic medical records: barriers and solutions. Health Aff (Millwood). 2004;23(2):116-26.

2. Wang SJ, Middleton B, Prosser LA, Bardon CG, Spurr CD, Carchidi PJ, Kittler AF, Goldszer RC, Fairchild DG, Sussman AJ, Kuperman GJ, Bates DW. A cost-benefit analysis of electronic medical records in primary care. Am J Med. 2003;114(5):397-403.

3. DesRoches CM, Campbell EG, Rao SR, Donelan K, Ferris TG, Jha A, Kaushal R, Levy DE, Rosenbaum S, Shields AE, Blumenthal D. Electronic health records in ambulatory care: a national survey of physicians. $\mathrm{N}$ Engl J Med. 2008;359(1):50-60.

4. [Internet] Wikipedia; the Free Encyclopedia. Electronic Health Record. http://en.wikipedia.org/wiki/Electronic_patient_record

5. Lionis C, Symvoulakis EK, Vardavas CI. Implementing family practice research in countries with limited resources: a stepwise model experienced in Crete, Greece. Fam Pract. 2010;27(1): 48-54.

6. Moth G, Olesen F, Vedsted P. Reasons for encounter and disease patterns in Danish primary care: changes over 16 years. Scand J Prim Health Care. 2012;30(2):70-5.

7. Mäenpää T, Asikainen P, Gissler M, Siponen K, Maass M, Saranto K, Suominen T. The utilization rate of the regional health information exchange: how it impacts on health care delivery outcomes. J Public Health Manag Pract. 2012;18(3):215-23.

8. van den Bussche $H$, Schön G, Kolonko T, Hansen H, Wegscheider K, Glaeske G, Koller D. Patterns of ambulatory medical care utilization in elderly patients with special reference to chronic diseases and multimorbidity--results from a claims data based observational study in Germany. BMC Geriatr. 2011 Sep 13;11:54.

9. Calderón-Larrañaga A, Gimeno-Feliu LA, Macipe-Costa R, Poblador-Plou B, Bordonaba-Bosque D, Prados-Torres A. Primary care utilisation patterns among an urban immigrant population in the Spanish National Health System. BMC Public Health. 2011;6:11.

10. Glynn LG, Valderas JM, Healy P, Burke E, Newell J, Gillespie P, Murphy AW. The prevalence of multimorbidity in primary care and its effect on health care utilization and cost. Fam Pract. 2011;28(5):516-23.

11. Andersen RM. Revisiting the behavioural model and access to medical care: Does it matter? J Health Soc Behav. 1995;36:1-10.

12. Abu-Mourad T, Alegakis A, Shashaa S, Koutis A, Lionis C, Philalithis A. Individual determinants of primary healthcare utilization in Gaza Strip, Palestine. J Epidemiol Com Health. 2008;62:701-7.

13. Kounalakis DK, Lionis C, Okkes I, Lamberts H. Developing an appropriate EPR system for the Greek primary care setting. J Med Syst. 2003;27(3):239-46

14. [Internet] International Classification of Primary Care, Second edition (ICPC-2). www.who.int/classifications/icd/adaptations/icpc2/
15. [Internet] WHO: International Classification of Diseases (ICD 10) www.who.int/whosis/icd10/

16. Mariolis A, Mercouris M, Lionis C. Introducing general practice in urban Greece: focus on morbidity profile. Eur J of Gen Pract. 2004;10:104-5.

17. Tsaxaki G, Katsapi Ch, Antonakis N. What are the problems encountered in the development of regional primary health care offices in urban areas? The experience of a regional medical office in an urban area. Primary Health Care. 2007;19(2):79-84.

18. Mariolis A, Alevizos A, Mariolis T. et al. Health needs assessment in special areas: an epidemiological study in the SouthEastern tip of continental Europe - The paradigm of Mani. Primary Health Care. 2007;19(2):69-78.

19. Mariolis A, Mihas C, Alevizos A, et al. Comparison of primary health care services between urban and rural settings after the introduction of the first urban health centre in Vyronas, Greece. BMC Health Serv Res. 2008;8:124.

20. Karatzanis A, Symvoulakis EK, Nikolaou V, Velegrakis G. Potential impact of the financial crisis on outpatient hospital visits due to otorhinolaryngologic disorders in Crete, Greece. Int J Med Sci. 2012;9:126-8. 